\title{
The Disappearance of Arthur Nestor: Parafiction, Cryptozoology, Curation
}

\author{
Kirsty Robertson
}

\section{Abstract}

This paper considers Beneath the Surface: The Archives of Arthur Nestor, a parafictional exhibition that I curated in 2014 with 16 undergraduate students at Western University, Canada. The exhibition depicted the life of Dr. Arthur Nestor, a professor of Biology who had disappeared from London (ON) in 1975, seemingly without trace. Over the summer of 2014, some of Nestor's files and artefacts had been discovered during university renovations, and this archive was given to students in Museum Studies to organize and catalogue. As we sorted through the files, it became clear that Dr. Nestor was something of a controversial figure, a man who became an environmental activist in Southwestern Ontario because of his belief that cryptids (lake monsters) lived in Lakes Huron and Erie, and were in need of protection from human-made pollution. As the documents in his file overlapped with our research in the wider sphere, the evidence seemed to suggest that Nestor had left London to join Dr. Roy Mackal, a University of Chicago professor of cryptozoology searching for the Loch Ness Monster. This paper weaves together the tale of Arthur Nestor and the curating of Beneath the Surface with a history of the relationship between natural history museums and cryptozoology, ultimately questioning what parafiction can do in both art galleries and museums.

Key words: parafiction, contemporary art, cryptozoology, pedagogy, natural history museums, collecting, collections, British Museum, Loch Ness Monster, Natural History Museum (London)

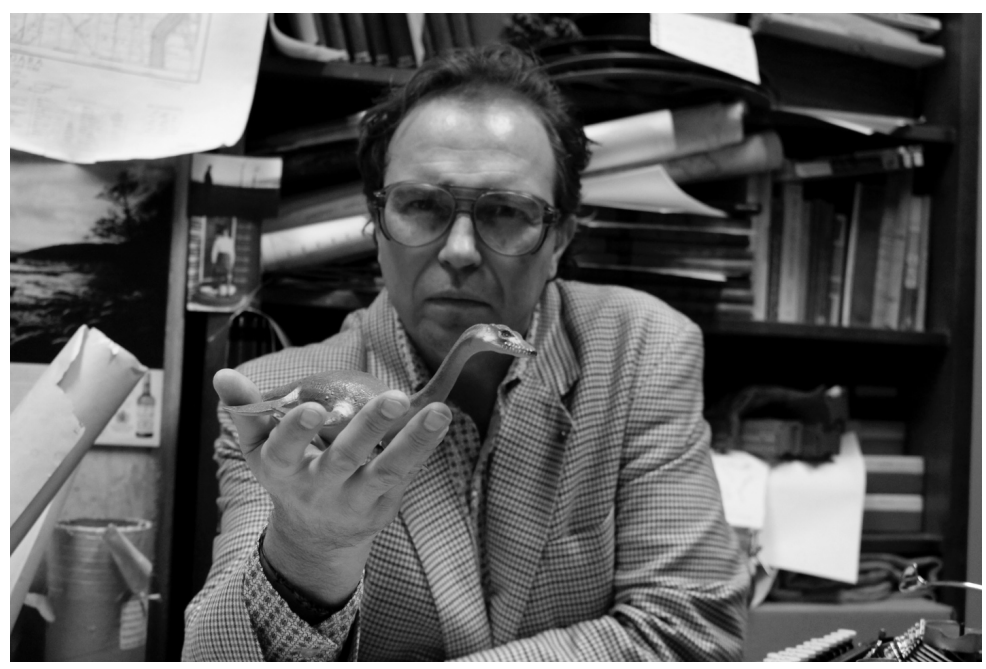

Figure 1. Arthur Nestor in his office, circa 1975, photo credit Mackenzie Sinclair 
Arthur Nestor was born in 1930 in the suburbs of Vancouver, British Columbia, Canada. After completing undergraduate and graduate degrees in Biology and Zoology, Nestor moved to Southwestern Ontario, and in 1967 he began a professorship at the University of Western Ontario (Western) in the Department of Biology, studying pollution levels in nearby lakes Erie and Huron. In the late 1960s, he met Bonnie Haussler, a science fiction writer from Tilsonburg, Ontario, and the two were soon engaged. Tragically, Haussler died in a car crash in 1969. In 1975, Dr. Arthur Nestor disappeared without a trace. ${ }^{1}$

Nearly forty years later, in the summer of 2014 , I received a phone call from Facilities Management at Western. A campus superintendent told me that during renovations of the Arts and Humanities building at University College (an iconic stone tower at the centre of campus), the papers of several former professors were discovered. The boxes were offered to the university archives but had been turned down due to lack of space. A few contained some items that he thought I 'might want for the museum studies students'. Although I had little interest in what I supposed would be the notes of a long-retired art historian, I nonetheless made my way up the hill in the hot Ontario summer.

The building was a mess. Six or seven boxes covered in cobwebs and dust had been hauled out from a soon to be demolished room and set aside from the massive pile of garbage that was being transferred out a window into a dumpster. I opened a box with the name Arthur Nestor written on it, and saw, to my surprise, not documents but a dried Tetraodontidae (puffer fish) specimen sitting on top of what appeared to be a desiccated plant, a small model of a plesiosaurus, and numerous documents. I didn't stop to look through the other boxes, I just said yes, I was interested, and the boxes were delivered to the Visual Arts Building a few days later. I Googled the name Arthur Nestor, and nothing of use showed up. A search of the Western website turned up nothing. A search of the Western Gazette, the long-running student undergraduate newspaper, also turned up nothing. Finally, I went to ARCC (the Archives and Research Collections Centre) to read the London Daily News, a student-run community newspaper that had been around in 1975 but no longer existed. There I found two articles outlining Nestor's career and his disappearance, one from December 1975, and a second from January 1976.

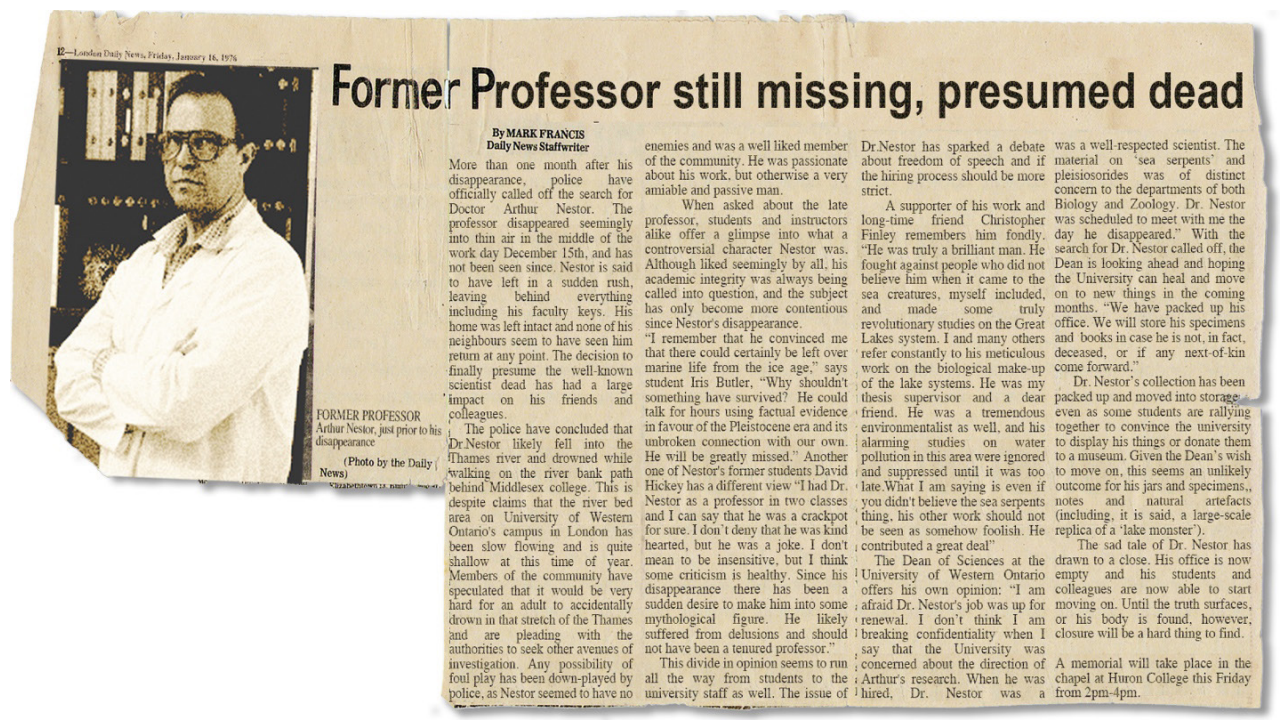

Figure 2. London Daily News article documenting Arthur Nestor's disappearance, January 16, 1976 
Dr. Arthur Nestor vanished in late 1975, and no one knew why. He had been a remarkably eccentric professor, known for his messy 'cabinet of curiosities' office. In the January 1976 story, which documents the ongoing search for the professor, the Dean of Sciences seems somewhat relieved at Nestor's departure, noting that he was concerned about the direction of Nestor's research. That research is also covered in the December 1975 newspaper article, which documents Nestor's interest in the possibility of cryptids, or lake monsters, living in lakes Erie and Huron. His widely published research into environmental impacts on the lakes drew from his unshakeable belief that high pollution levels in the 1960s and 70s were directly correlated with the decreasing number of sightings of 'Bessie,' a monster often spotted in Lake Erie who was noticeably absent in those decades.

These two newspaper articles gave sense to the archival boxes, which were full of specimens, scribbled notes, and research on Loch Ness. Nestor had multiple, heavily annotated copies of an infamous article published in Nature in 1975, showing compelling photographic evidence of a creature in Loch Ness. He also had a proof copy of University of Chicago biologist Dr. Roy Mackal's book on 'Nessie' (which Mackal believed to be a zeuglodon, a prehistoric serpent-like creature). There was also correspondence with Mackal, maps of the area around Loch Ness, tourist guides for Scotland, and dozens of notes documenting and pontificating on the relationship between Loch Ness and the Great Lakes, comparing silt levels, pollution levels, depth of the water, and other variables. It was easy to make the leap: perhaps Nestor had left London, Ontario, to search for the Loch Ness monster with Mackal, who worked in Scotland until the late 1970s, founded the International Society for Cryptozoology in Washington, DC, and travelled to Africa to seek Mokele Membe, a cryptid lake monster allegedly living in the swampy area at the centre of the Democratic Republic of Congo. What had been a dusty and discarded archive came completely alive.

Only, it didn't.

Arthur Nestor doesn't exist. He never existed. University College was undergoing renovations in the summer of 2014. University College was a Natural Sciences Building in the late 1960s, and had Nestor existed, he likely would have taught there and had an office in the building. Dr. Roy Mackal did exist; he was a cryptozoologist who worked at the University of Chicago, and he did direct the Loch Ness Bureau of Investigation. The later disavowed photos of the Loch Ness monster were published in Nature in 1975, and they did cause a splash. ${ }^{2}$ Everything else was a fabrication; a parafiction (Lambert-Beatty 2009), or fictive exhibit (Le Couteur 2015), designed to tell the story of Arthur Nestor.

Every year, Western offers a curatorial practicum for undergraduate students in their final year. This culmination of our major in museum and curatorial studies results in an exhibition curated by students, with a budget of about $\$ 3,000-\$ 4,000 \mathrm{CDN}$. The class has some interesting considerations - it is neither connected to a museum nor to a collection (both of which are more typical of undergraduate exhibitions classes). Consequently, the exhibitions tend to be conceptual, experimental, and speculative. Over the years they have included the construction of giant shadow puppets, a sound walk through London, Ontario, and a moonscape/moon museum in the gallery. The course's purpose is to unleash students' creativity. Having spent three years learning the ins and outs of collections management and exhibition design theory, the fourth-year class encourages students to think about how to bring their research to various audiences through unorthodox means.

The Arthur Nestor exhibition, ultimately titled Beneath the Surface: The Archives of Arthur Nestor, centred on the creation of the persona of Arthur Nestor and the story surrounding his disappearance, both told through objects and ephemera. ${ }^{3}$ Nestor himself could only be present as a ghost in the space of the gallery. Underpinning the creation of Nestor were three interwoven 'subplots': Nestor's studies of pollution in the Great Lakes; museums' history (particularly that of museums that blend[ed] fact and fiction); and cryptozoology (a term coined in 1955 by French scientist Bernard Heuvelmans, and defined as 'the scientific study of hidden animals, i.e. of still unknown animal forms about which only testimonial and circumstantial evidence is available, or material evidence considered insufficient by some') (Simpson 1984: 1; Hurn 2017). To build Nestor's backstory, we therefore had to explore 
how he might have come to believe in lake monsters, why he might have sought the Loch Ness monster, and what beliefs regarding cryptids were common at the time that we set his story. The production of this exhibition had three main goals: first, to create an entertaining fictional tale designed to bring visitors to the gallery; second, to use the story of Arthur Nestor to present information about historic and current pollution in the Great Lakes; and third, to introduce students to museum histories, ethics, and exhibition development in a challenging but compelling manner.

In this essay, I use Beneath the Surface as the starting point for a wider exploration of museum histories, pedagogy, and parafiction. Parafiction, a term introduced by Carrie Lambert-Beatty in 2009, refers to artworks and exhibitions that reside in the space between fact and fiction. The parafictional creation of Arthur Nestor coalesced around discussions of how museums integrate storytelling; it also crossed over into how major institutions such as the British Museum/Natural History Museum in London (UK) as well as the Smithsonian were caught up (sometimes against their will) in the search for the Loch Ness monster around the time Arthur Nestor ostensibly disappeared. Our work inevitably led us to research how many museums have been built atop hoaxes and humbug designed to bring visitors through the doors, a practice that invokes ethical concerns. Finally, we nestled Nestor's story into the issue of pollution in the Great Lakes region. This last 'fact' was a 'truth', but it functioned as the impetus for Nestor's disappearance through his concern for suffering cryptids, and as a lived reality of students in the class and visitors to the exhibition. This aspect of the exhibit added complexity to its thematics and allowed us to ask new questions about museum hoaxes: what if they are in service of an activist aim? While I felt very strongly about the inclusion of information about lake pollution, as the exhibition opened, the activist aims of the exhibition were pushed aside, and it seemed that interest centred largely on whether Nestor was real. Had we positioned the exhibition differently, letting visitors know from the outset that its main character was fictional, what would have differed? Ultimately, I argue that the multiple layers and stories of the exhibition obscured a clear message but, nonetheless, the exhibition succeeded on multiple levels, firstly in terms of audience attendance, but most importantly in terms of a learning/teaching experience, wherein the museum histories and considerations of lake pollution that were the background in situ were the foreground in the classroom.

Like all exhibitions, Beneath the Surface was an exercise in paring down information and in carefully selecting what could and could not be shown. Had we made different decisions, focusing on the subplots rather than on Nestor himself, would the exhibition have had a similar impact? In building the story that would underpin the Beneath the Surface exhibition, we were constantly confronted with the limits of 'truth' and fact, and with the way that fiction and storytelling can entice in ways that are educational and magical, but also questionable and possibly underhanded. This essay explores these issues, reanimating some of the backstory that was edited from the exhibition. I focus on parafiction as well as the exhibition as a pedagogical undertaking and conclude by noting how a changed world has affected my impressions of Beneath the Surface.

\section{Parafiction}

Beneath the Surface: The Archives of Arthur Nestor opened in February 2015 in the Artlab Gallery housed in the Visual Arts Department at Western University. ${ }^{4}$ Visitors were told the story of Arthur Nestor in a number of ways. The exhibition centred on a reconstruction of his office, filled with furniture and objects from the 1970s that had been collected from departments across campus. ${ }^{5}$ The Biology Department loaned specimens and allowed us to take photographs of Nestor (played by a delighted professor of cell biology) in their archives. A librarian who had been collecting material ephemera since the 1950 s lent us a card catalogue, date stamp, office supplies, and other objects that added authenticity to the office. ${ }^{6}$

The class created a facsimile of an Amazon.com page advertising Bonnie Haussler's out-of-print books and a newspaper article documenting her untimely death. My mother loaned an album of photographs of her emigration from London, UK, to Vancouver in the 1960s; we used this artefact to give Bonnie Haussler a face. In a fictive article published in the exhibition catalogue describing the life of Arthur Nestor, student Keely McCavitt posited that perhaps Bonnie's death led Nestor to abandon his position at the university for Scotland. 


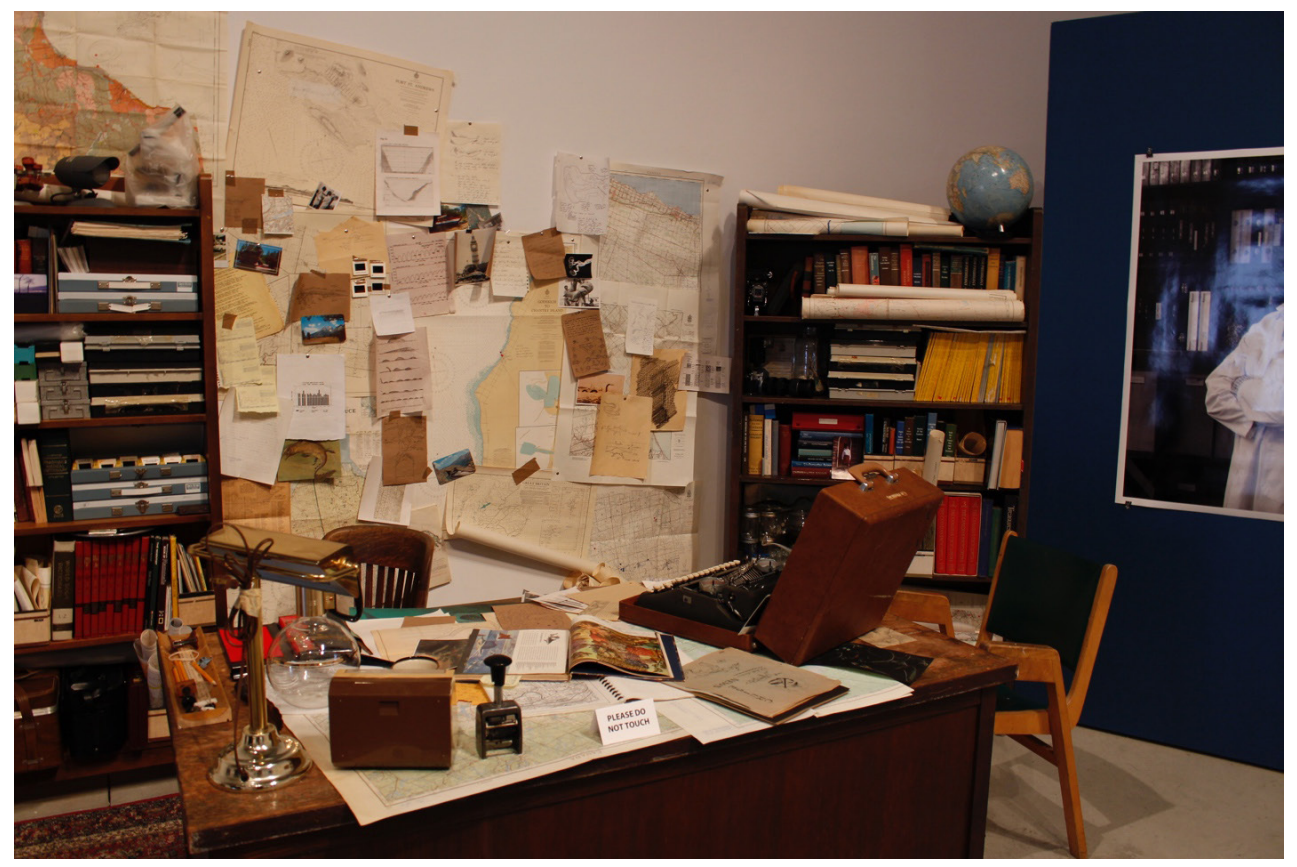

Figure 3. Beneath the Surface: Archives of Arthur Nestor installation shot, detail, February 2014, photo credit Mackenzie Sinclair

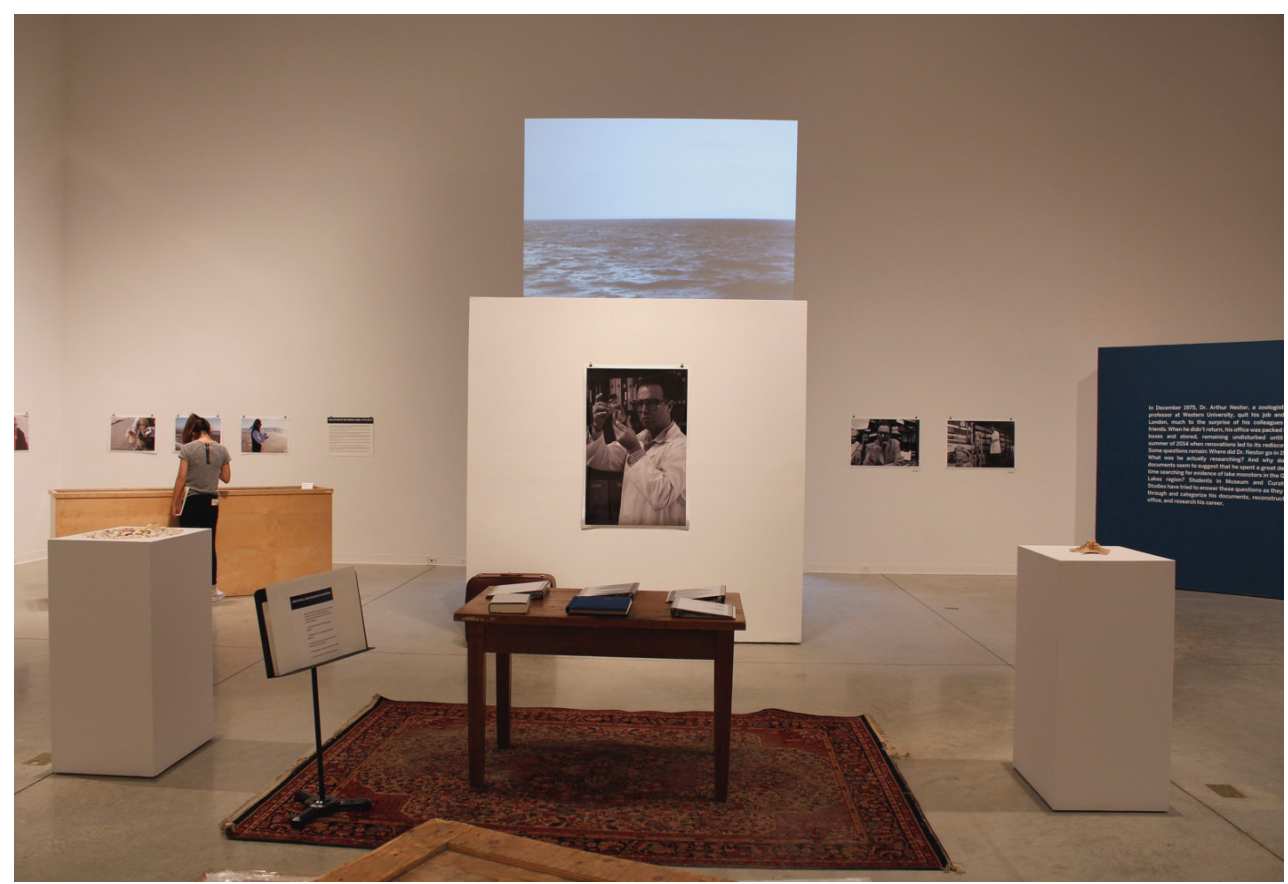

Figure 4. Beneath the Surface: Archives of Arthur Nestor installation shot, detail, February 2014, photo credit Mackenzie Sinclair 
In turn, the story of this trip was told through 'clues' students had purportedly discovered in the paper archive: maps of Loch Ness, a hastily scribbled note documenting flights from Toronto to Scotland, and numerous articles and pieces of ephemera dedicated to the Loch Ness 'phenomena'. Also included were Nestor's research files - articles from the 1960s and 70 s documenting pollution in the Great Lakes, as well as a few 'altered' abstracts ostensibly describing Nestor's research. Newspaper articles about Bessie (Lake Erie), Champ (Lake Champlain), and 1960s and 70s ephemera dedicated to sea and lake monsters rounded out the exhibition, which also included a crate containing the evocative remains of an oar fish/'monster', created from rubber and an old fire hose by student Erik Skouris. Together these artefacts, or as I define them later in this paper, art-facts, provided the framework for the parafiction of the exhibition.

Though defined by Lambert-Beatty relatively recently, parafiction has long been a popular strategy in art production as a way to use objects or installations to tell stories. According to Lambert-Beatty (2009: 54), parafiction is related to the category of fiction '[but] unlike historical fiction's fact-based but imagined worlds, in parafiction real and/or imaginary personages and stories intersect with the world as it is being lived'. Similarly, Elizabeth Armstrong (2013: 56) calls parafiction 'a form of reality excavation, in which [artists] take on fictional identities to tell stories based on factual events'. Take, for example, artist Mark Dion's Curator's Office (2012-13) at the Minneapolis Institute of Arts (an important inspiration for Beneath the Surface). Visitors to Dion's installation encountered a curator's office, accidentally sealed behind a door painted shut in the 1950s and rediscovered in 2012. The office belonged to Barton Kestle, the (fictional) first curator of modern art who disappeared after boarding a train to Washington, DC. Clues in the office (including a paper summons) suggested that Kestle's disappearance might be linked to his being called to testify at a session of the Senate Permanent Subcommittee on Investigations chaired by Senator Joseph McCarthy (Armstrong 2013: 56). ${ }^{7}$ The parafiction of the curator's office was presented as a memorial to those affected by McCarthyism (Armstrong 2013: 56). ${ }^{8}$

Parafiction has much in common with what Hal Foster terms 'archival' art, or artworks that 'share a model of artistic practice as an idiosyncratic probing into a particular figure, object, or event in modern art, philosophy, or history' (Foster 2017: 31). ${ }^{9}$ Examples include Tacita Dean's semi-fictional reconstruction of the passage of stowaway Jean Jeannie who, in 1928, hid on a ship bound from Australia to England; Lee Wan's Mr K., which attempts to rebuild a life from a photographic archive that Wan found at a Korean flea market; or Gerard Byrne's research-laden project documenting searches for the Loch Ness monster (Foster 2017: 42). Both start with the 'real' - the difference is that archival works use that event to continue to excavate a 'real' past, while parafictions use the 'real' to create something new.

Beneath the Surface came together at a moment when parafictional artworks and installations seemed to be everywhere in the art world, drawing attention to the ways in which exhibitions have always included untruths and exposing the conventions that have hidden omissions, exaggerations, minimizations, and outright lies. The class was deeply inspired by the work of Iris Häussler as the majority of students had seen her installation He Named Her Amber at the Art Gallery of Ontario ${ }^{10}$ (and many had believed it to be true, thus giving them insight into how visitors might experience our exhibition).

While having elements in common with Häussler and Dion's work, there were important distinctions in the students' endeavour, most notably the inclusion of materials on museum histories, cryptozoology, and research around lake pollution. Moreover, Beneath the Surface was not installed in a museum with dedicated personnel. The environment was not immersive, and no tour guides steered viewers towards significant information or away from weak points in the narrative. It also had a minute budget in comparison to the examples introduced above and the audience was comparatively small and local. The exhibition also emerged not from an established art practice but from a class, one of five most students were taking. Though all students participated enthusiastically, some contributed more extensively to story-building than others. Thus, one peculiarity of the exhibition was that the story of Nestor was created by a fairly large group of people who were invested in the class to greater or lesser extents; some understood Nestor and his work on lake pollution down to the tiniest detail while others held a vaguer comprehension. 
This unevenness was mirrored in the construction of the exhibition. Beneath the Surface allowed participant/viewers to shift in and out of the story, moving among photos and 'archival' objects, a recreation of Nestor's office, and real historical artefacts. Students pretending to replicate one of Nestor's experiments photographed themselves on the shores of Lake Erie, and we included extensive information about pollution levels in the lake in 1975 and in 2014. Decisions made throughout profoundly affected the direction and outcome of the exhibition. For example, one aspect that led to in-depth discussion was the way that fiction can actually be more normative and parochial than fact - as a case in point, the majority of the class argued strongly that Nestor had to be white and male in order to be believable. Actually, numerous professors at Western in the 1970s did not fit that profile.

While students decided by consensus that they did not want to advertise the exhibition as fiction, they were not asked to lie. Some decided to give away nothing; others revealed the fiction. Because of these differences from the work of Dion, Häussler, and others, Sophie Quick (the teaching assistant) and I spent considerable time managing expectations and trying to work with students to mitigate their disappointment should visitors not believe that Arthur Nestor's story was factual.

But we were wrong. Beneath the Surface did achieve a 'truth status', (Lambert-Beatty 2012: 118) and the overwhelming (if fleeting) reception of the exhibition, especially on opening night, was that even when evidence presented was clearly compromised, anachronistic, or just plain bizarre, people stretched to believe in Nestor. Some visitors left the exhibition unsure, and some unquestionably believed Nestor to be real. For others, especially students with friends in the class or who recognized photo-editing techniques, the parafiction was seen and admired for what it was. Anecdotal evidence suggested that few believed the cryptozoological claims of the exhibition - Nestor's supposition that the Loch Ness monster existed. Yet, while visitors did not believe in Nessie, some were persuaded that a trained biologist working in the 1970s did. Perhaps visitors did not want to work through more than one level of fiction/ untruth, but it almost seemed that Nestor's unorthodox beliefs made him more ... believable.

Clearly, we had underestimated the pull of wanting to believe in a story. As LambertBeatty notes,

Parafictioneers produce and manage plausibility. But plausibility (as opposed to accuracy) is an attribute not of a story or image but of its encounter with viewers, whose various configurations of knowledge and 'horizons of expectation' determine whether something is plausible to them (Lambert-Beatty 2012:135).

Visitors to Beneath the Surface wanted the story to be true (and wanted this exciting event to have happened at the university), and so, for a time, and for some, it was.

In exhibitions that produce 'fact' through fictive means (Le Couteur 2015: 36$)^{11}$ it is inevitable that certain 'facts' will gain traction and that the story will fragment into diverse narratives constructed by each separate visitor. While arguably all exhibitions have more or fewer interpretive elements, when the exhibition is a story and vice versa, the experience determines whether the logic of storytelling is plausible or not. The tropes of conventional museums - artefacts, labels, and so on - become part of the layered performance, affirming the 'truth' of the scenario, while simultaneously undermining it (McLeod 2013; Le Couteur 2015: 36). What is distinctive about parafictional or archival exhibitions is the extensive backgrounds that are created as scaffolding for the conveyance of narrative. Real objects used to tell stories become art, or what I call art-facts, and strange stories either gel or fall apart based on the way that visitors move through the space, accessing and amassing information that is often dedicated solely to upholding the story. Parafictional exhibitions fold in extensive amounts of research that is unevenly available to viewers. Häussler's use of tour guides, for example, works at least partially to control flows of information and to make sure that the project is fulsomely experienced by participants.

Parafictions and their plausibility are made and unmade in the moments of contact between visitors and artefacts/art-facts. While such relationships can create compelling and delightful moments, parafictions are always only partial - both in their relationship to a supposed 'truth' and in their relationship to the research that went into their making. The quest to determine whether the exhibit's information is 'true' can overwhelm its other aims - 
the incredible detail and multilayered nature of parafictional exhibits paradoxically obscures all of the research that might have gone into creating the details that add to the plausibility. To explore this issue, I bring forward major aspects of the work behind Beneath the Surface that stayed largely in the background during the exhibition.

\section{Beneath the Surface, Hoaxes, and Humbugs}

The inspiration for the exhibition lay partly in parafictional art works and partly in the history of cabinets of curiosity and huckster museums that crossed the line between fact and fiction. Such histories were largely new to students and directly affected the class's exploration of museums as both authoritative (particularly in terms of nineteenth-century museums) and anti-authoritative (particularly in terms of dime museums and other prankster establishments).

Students were inspired by the sense of wonder that natural history collections could provoke. As Rachel Polliquin (2012: 16) writes of the mid-sixteenth century,

Collectors mingled artifacts indiscriminately in chaotic displays of visual delight. Strange fish and mummified reptiles hung from the ceiling, stuffed birds and mammals lined the walls, shells and dried reptiles were arranged in drawers, and pickled sea creatures stood in glass jars in open cabinets. After all, the driving momentum behind such cabinets of wonder, or wunderkammern, as early collections were known, was to provoke wonder at the dizzying variety of nature.

Students loved this passage; we briefly considered including it in the exhibition because it captured their desire for visitors to appreciate how facts of natural history could be stranger than fiction.

As cabinets of curiosity gave way to the amassing of large collections and eventually to the building of large-scale museums, some things remained unchanged. As Benjamin Reiss (2010: 110) notes, quoting Lawrence W. Levine, from the time proto-parafictioneer P.T. Barnum's fame was ascending in the mid-nineteenth century,

In a typical museum, one could find a piece of wood from Noah's ark, wax figurines of notable personages, stuffed animals, dinosaur bones, a 'monstrous tapeworm' extracted from a human intestine, and mummies alongside masterworks of art; in addition, singing dwarfs, ventriloquists, magicians, operators of diorama and other contraptions, and lecturers on phrenology or craniology all found space to entertain and instruct their audiences.

Students were especially interested in Barnum's humbugs, most famously his 1842 display of the Feejee Mermaid (a monkey's desiccated upper body sewn onto the taxidermied tail of a fish). The Feejee Mermaid attracted huge crowds, many of them drawn by posters advertising a luscious and buxom blonde and white (at least from the torso up) mermaid (Bondeson 1999: 36-58). For students it seemed unbelievable that Barnum's ploy worked. But as we moved through the course material, it became increasingly obvious that it was not just at huckster museums that the line between truth and fiction was debated.

\section{As Béatrice Laurent (2017: 1) points out,}

In the early decades of the nineteenth century, while paleontologists were bringing to light indisputable proofs that species had existed and become extinct, many natural scientists were led to think that the fantastic animals which peopled classical mythologies were possibly not the fantasies of creative minds but lost species. In this context, the existence of mermaids hardly seemed more improbable than that of dinosaurs.

The numerous sightings of mermaids and monsters in historical records suggested that some unknown (except in myth and stories) species may have existed, or at least their existence could not be disproven. Laurent (2017:2) calls these moments 'definitional hesitations', pauses in the classification of the world. In short, in the museums of the late nineteenth century, even as better understanding of taxonomy, paleontology, and physiognomy made the identification 
of fakes easier, it was not so much that the line between fact and fiction was blurred as that it was not clear where that line lay.

It is no surprise that such collections inspired students in the class. Sixteenth century cabinets of curiosity and nineteenth century dime museums are in my experience always favoured course material. ${ }^{12}$ Students love learning about the mixture of 'magical' and natural history specimens in early collections and they love learning how the line between commercial entertainment 'museums' and the nascent natural history museums in the nineteenth century was porous. It was a time when 'natural history [was showcased] as a carnival for the curious, a theater of imaginative possibilities [where] ... A large speculative margin accompanied scientific knowledge, and ... playing in the margins was a more-than-acceptable pastime for new learners' (Pandora 2017: np). Such lessons appeared in Beneath the Surface where actual zoological specimens borrowed from the Biology department and relabelled as having been retrieved from Nestor's archive added a layer of authenticity. But the oar fish/'monster', made from a painted rubber hose and stored in a battered crate, stretched credulity. Like

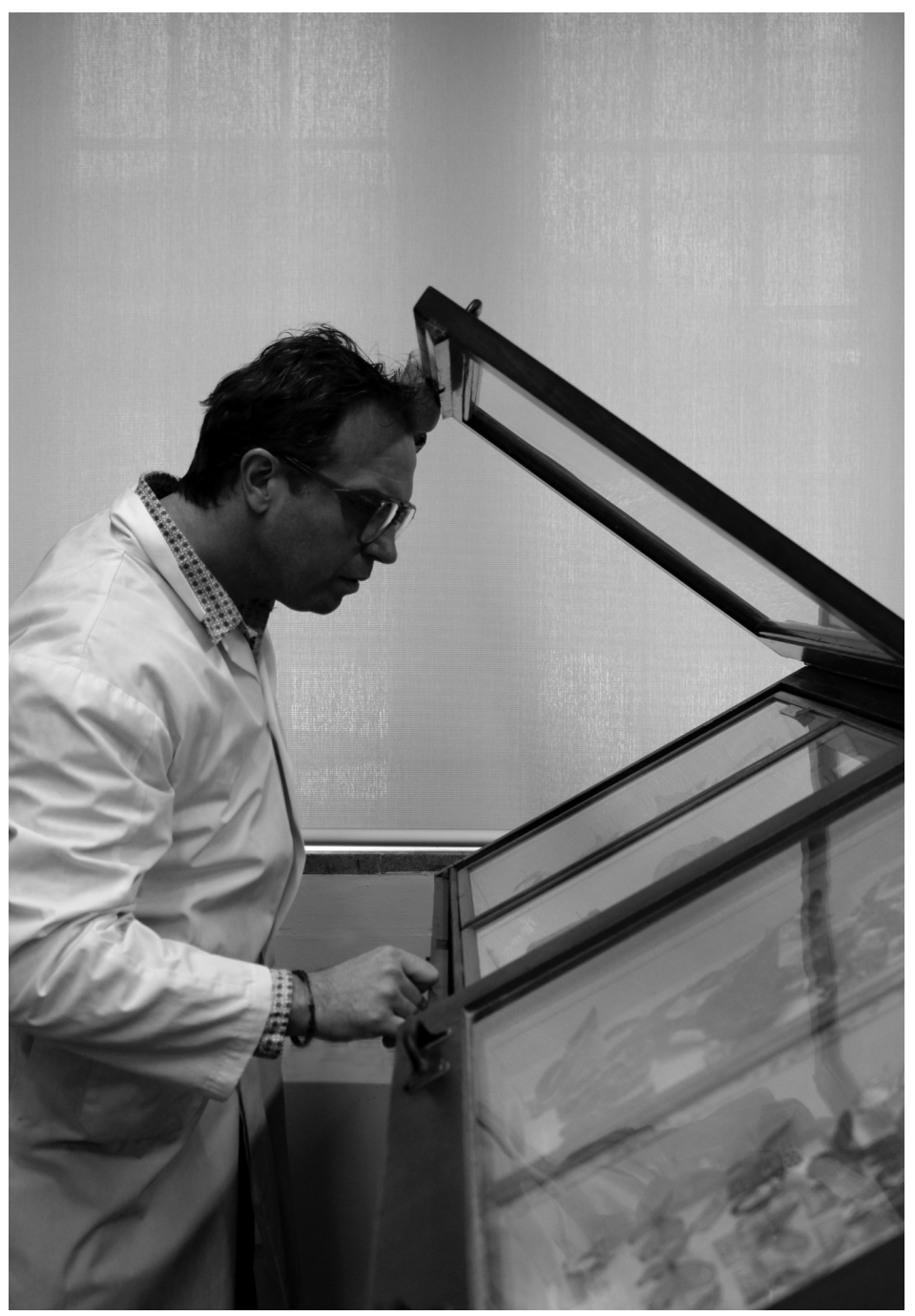
the Feejee mermaid, it acted as a humbug. Students hoped that because it appeared so fake, viewers may have surmised that it was a contemporary replica of a 'real' object from Nestor's archive. Setting up Arthur Nestor's stand-in in front of the traditional butterfly display cabinet in the Biology Department at Western University, I was aware of the pull of natural history collections in creating a parafiction. I was also aware that most of the background information was as fleeting as the lifespan of the butterflies Nestorwas examining. We could include indexical referents and clues to what we had learned, but even the most astute viewers could not read minds (particularly the minds of eighteen curators working together as a class, teaching assistant, and professor). But we could capture a sense of wonder.

Figure 5. Arthur Nestor examining the butterfly collection, photo credit Mackenzie Sinclair 
The fluidity of fact and fiction in the nineteenth-century natural history museum contributed to the debates about the veracity of our exhibit. But there is an issue here, for in setting themselves up as reliant on physical evidence and separating themselves from the hoaxes and humbug such as the Feejee Mermaid (which remains in a natural history museum as evidence of past folly), natural history museums have become by proxy the judges of whether something is 'real'. And as such, they ultimately tied themselves to cryptozoology, partly through naming newly described species, and partly through becoming the 'voice of reason' when it comes to authenticating sightings of charismatic cryptids such as the Loch Ness monster and Sasquatch. This tendency is one of the reasons that the cryptid layer of our exhibition might have seemed credible to viewers; it was situated in a place they considered authoritative, and assumed its mantle of credibility. For Arthur Nestor, why should the Loch Ness monster (or monsters) not be the last of its/their species, a plesiosaur that escaped the demise of its brethren (an idea that maintains traction to this day)? Beneath the Surface offered a way to explore how debates over the existence of monsters continue to play a role even in the most seemingly staid institutions.

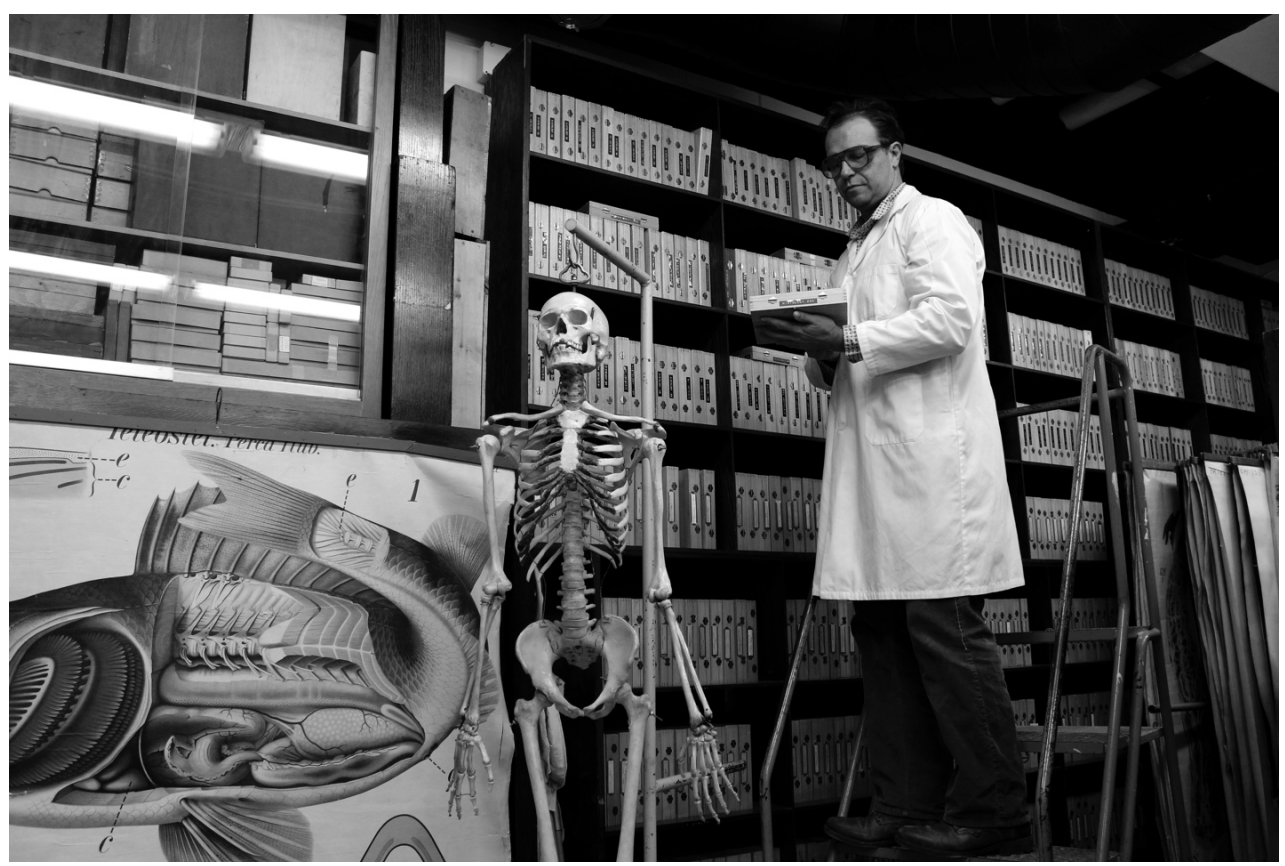

Figure 6. Arthur Nestor in the Zoology Collection, photo credit Mackenzie Sinclair

\section{Loch Ness Monster Research, Layering, and Climate Pedagogy}

Cryptozoology offered a way to present visitors with the complexities of definitions in natural history studies as well as to create the second layer of our parafiction. In this way, it also allowed us to explore how museums negotiate issues of authority and authenticity in visitor encounters. Originally, we chose 1975 for Nestor's disappearance because it was sufficiently recent that we could obtain contemporary artefacts inexpensively, but far enough away that no one was likely to remember whether the missing professor had existed..$^{13}$ It turned out that 1975 was an auspicious choice because it fell in a time of heightened interest in the Loch Ness monster. As W.H. Lehn wrote in Science in 1979, 'Modern sightings [of lake monsters], too frequent to be ignored, have intrigued many scientists' (Lehn 1979: 183). Although reports of water horses (each uisge) in Scottish lochs date back thousands of years (Magin 2016: 212), ${ }^{14}$ the term monster became popular in the 1930s when a road was built along the northern edge of Loch Ness and sightings increased..$^{15}$ 


\section{PBS reported:}

The excitement over the monster reached a fever pitch in December [1933], when the London Daily Mail hired an actor, film director, and big-game hunter named Marmaduke Wetherell to track down the beast. After only a few days at the loch, Wetherell reported finding the fresh footprints of a large, four-toed animal. He estimated it to be 20 feet long. With great fanfare, Wetherell made plaster casts of the footprints and, just before Christmas, sent them off to the Natural History Museum in London for analysis. While the world waited for the museum zoologists to return from holiday, legions of monster hunters descended on Loch Ness, filling the local hotels. Inverness was floodlit for the occasion, and traffic jammed the shoreline roads in both directions. The bubble burst in early January, when museum zoologists announced that the footprints were those of a hippopotamus. They had been made with a stuffed hippo foot-the base of an umbrella stand or ashtray. It wasn't clear whether Wetherell was the perpetrator of the hoax or its gullible victim. ${ }^{16}$

Stories such as these were of great interest to students, and we tried to incorporate them into the exhibition as much as possible. Information on the Loch Ness monster was easy to include in Beneath the Surface. Much of it is in the public domain, readily accessible in magazines, books, and pamphlets, most of which could be acquired and displayed. With our help, Nestor became an audacious collector of 1970s bric-a-brac, articles, clippings, postcards, and maps. Because we relied on local antique stores and 2014 eBay auctions, he was an opportunistic archivist and a collector with abiding interests in cryptozoology and lake pollution, as well as a sense of humour with regard to Loch Ness paraphernalia and souvenirs. Included in his collection were articles related to searches for the Loch Ness monster, including coverage of Wetherell's visit.

Here, the history of cryptozoology enabled us to indicate how science and fantasy merged in early natural history. Cryptozoology was the purview of amateurs (such as Nestor), and the results of their work needed evaluation, almost always by a representative of an authoritative museum. Photographs taken in 1972 and published in the infamous 1975 Nature article that was used in Beneath the Surface provide a case in point. The original photos were taken by a team from the Academy of Applied Science in Boston, working with the Loch Ness Investigation Bureau of London (to which we posited Nestor was en route). Two underwater photographs were computer enhanced at the Jet Propulsion Laboratory in Pasadena, California (Scott and Rines 1975: 466). The Nature article analyzes the photographs, trying to ascertain from them the anatomy of the monster. But despite the frenzy that followed the publication of photographs, the article was greeted by the Natural History Museum, London (UK), with a statement that nothing had been proven. The museum's measured response did little to quell interest, suggesting that the public was in love with novelty. We thought, "how compelling, how believable that Nestor might want to go'. Behind the scenes of the exhibition, we understood this call implicitly. And so, too, the audience, without knowing the ins and outs of 1970s Loch Ness monster research, seemed convinced that yes, Nestor might have disappeared to Scotland. This was in part because as amateur scientists partnered with well-funded university and private expeditions, forays into Loch Ness became increasingly sophisticated and occasionally bizarre. Plenty of column space in peer-reviewed articles written by scientists like Nestor was dedicated to debating whether there were sufficient food sources in Loch Ness to support a plesiosaur; what it meant to have never discovered any tangible physical/zoological evidence (teeth, scales, carcasses, for example); and whether the mass of a plesiosaur would change water levels in Loch Ness. Even Carl Sagan weighed in, using collision theory to estimate how often searchers for the Loch Ness monster would actually encounter the real thing (Lawton 1996). We included many of these articles in the exhibition. Local history further bolstered the case for Nestor's compulsion to find Nessie. Interest in the Loch Ness monster was global, and in Ontario, not far from Lakes Erie and Huron, scientists and interested lay scholars worked in the early to mid-1970s to figure out how to prove whether Nessie existed (Schneider and Wallis 1973: 343).

The Loch Ness monster also enabled us to pursue one of our pedagogical aims for the show - to draw attention to pollution damage to lakes. 
Dendle argues that a rise of interest in cryptozoology allows proponents

to channel guilt over the decimation of species and destruction of the natural habitat; to recapture a sense of mysticism and danger in a world now perceived as fully charted and over-explored; and to articulate resentment of and defiance against a scientific community perceived as monopolising the pool of culturally acceptable beliefs (Dendle 2006: 190).

This was a thread we picked up on with Arthur Nestor. His fear that pollution in the Great Lakes was making Lake Erie uninhabitable for Bessie echoed contemporary fears that pollution, climate change, and other hazards might profoundly affect cryptids as well as the humans living around the Lakes' perimeters (Magin 2016: 215-6).

Using cryptids as a basis to call for protection was not unique to Nestor and Bessie. Calls for the protection of Champ were met with legislation from the New York State Assembly in an April 1983 'resolution [to] protect Champ, promote serious scientific enquiry into the Champ phenomenon and encourage individuals to report sightings' (Zarzynski 1984: 120). The same was true in Loch Ness. Sir Peter Scott was not only involved in the 1975 Nature article but was also the founder of the World Wildlife Fund. While the impetus of the Nature article was to show conclusive evidence for the presence of a phenomena in Loch Ness, 'Scott and his co-author, the American Nessie enthusiast Robert Rines, named the creature Nessiteras rhombopteryx with the intention that it could then be pre-emptively protected under the Conservation of Wild Creatures and Wild Plants Act 1975'.17 Under UK law, a scientific and a common name are required for a species to be protected (Lawton 1996: 378).

While Beneath the Surface made room for the kind of scepticism towards lake monsters demonstrated by the Natural History Museum, London (UK), the continued presence of museums in cryptid searches allowed for a coming together of our pedagogical intents teaching about museum histories and the environment with the creation of a parafictional exhibition. That much of that information was missing in the final exhibition directed visitors away from the interpellation of museums with some of the key subplots of the exhibition, and towards the biography of Nestor. While much of the above information was available as 'clues' in the exhibition space, without tour guides or classroom lectures, its impact dissipated such that the story of Nestor, and then the question of whether he was real, overwhelmed all other aspects of Beneath the Surface.

\section{Conclusions for a Different World}

Beneath the Surface alluded to three distinct time periods - 1975-76, when the exhibition was set; 2014, when it was installed in the gallery; and 2019 when I reflected back on it. Now I feel quite differently about the ethics of the parafictional elements of Beneath the Surface than I did a mere five years earlier.

The presence of the Loch Ness monster in Beneath the Surface should have signalled the story's dubious relationship with veracity. In organizing the exhibition, we all made an erroneous assumption that most visitors would immediately see the exhibition for the artwork that it was. We did not conduct exit surveys, and therefore it is difficult to say whether visitors felt 'duped' or 'awed' (two comments recorded from visitors to Iris Häussler's He Named Her Amber) (MacKay 2009: 83). I talked with many people at the opening-most were charmed by Nestor, by the story, and impressed with the students' work. Several hoped he might appear (I suspect they meant the professor who played him, but at the opening the lines between truth and fiction were blurry for everyone). One long-time supporter of the Visual Arts department expressed disappointment at having been 'tricked', while another visitor confronted the teaching assistant in a somewhat hostile manner, asking if 'we thought we were funny' (he left immediately afterwards). The story was covered as fact in a local newspaper and then quickly retracted when the publication discovered that it was an art project. And while word quickly spread among students and faculty that the exhibition wasn't 'real', enough people have asked me about Arthur Nestor in the years since that it is clear some people left the gallery believing in Nestor, his disappearance, and the search for the Loch Ness monster. Although I suspect the number of people crediting Nestor's story to be small, against our predictions, Beneath the Surface was 'plausible' (certainly not for all, but at least for some) (Lambert-Beatty 2013: 118). 
Since the election of Donald Trump in the United States and the rise of 'fake news', many of the issues that lay dormant in Beneath the Surface have come to the foreground.18 When Carrie Lambert-Beatty (2009) coined the term parafiction in the first decade of the 2000s, she was already tracing a relationship between parafiction and 'truthiness' - fake rationales for the invasion of Iraq, for example. She notes 'parafictional strategies are oriented less toward the disappearance of the real than toward the pragmatics of trust'. Layering parafictions complicated the issue. Some viewers clearly felt that we had broken their trust and their belief in museums as trusted public institutions. Others did not. Were I to organize the exhibition today, I would certainly give more consideration to presenting the exhibition as fiction, even if this meant missing out on the positives that I outline below.

I do not believe that there is a clear answer to what effect the exhibition had. In the case of Beneath the Surface, perhaps the exhibition 'encourage[d] a radical re-engagement with the performance of knowledge in the museum' as Le Couteur (2015: 36) suggests fictive museums can do, or perhaps it 'prepared us to be better, more critical information consumers and therefore citizens', as Lambert-Beatty suggests of parafiction (2013: 137). But it might just as easily have inspired in 'duped' viewers a wish for museums and galleries to convey only 'truth', to aspire towards impossible neutralities and deeply disguised biases, to resist any admission that labels or other didactics are stories even when they might not appear to be.

Nonetheless, I would like to believe Beneath the Surface inspired a sense of wonder, and I also remain convinced that, in 2014, parafiction was the best way to tell Arthur Nestor's story, for had we advertised it as fiction it would have encouraged a seeking out of fissures in the story rather than interest in its other aspects. On balance, students were aware of the implications of the exhibition, and we talked extensively about the ethics and reception of work such as Häussler's (MacKay 2009: 84). Although there are those who will always remain unconvinced, students in the class (even those who had experienced Häussler's work) accepted that her parafictional work is 'about enabling imagination. You give up intellectual control for a moment, and let yourself go' (MacKay 2009: 85). Nestor's story did shake a notion of an unchallenged and singular truth. But such notions were always already complicated by the exhibition's engagement with myth and storytelling through the Loch Ness monster and cryptozoology. Nestor's story was always one of slippage, one that exposed cracks in any kind of authenticity or search for 'truth'.

While the exhibition came to be defined by the overarching question of whether Nestor was real, the class imagined it as something more like: what happened to Arthur Nestor? a significant sematic difference. This slight (mis)translation on the part of visitors occluded layers of the exhibition; it misdirected away from the archive (unstable though it was) towards the fiction (or not/fiction). It also turned visitors away from the exhibition's material about lake pollution and back towards themselves, their expectations, their feelings, their boundaries.

I feel a great deal of tenderness for Arthur Nestor, who appeared driven from his job for his unorthodox beliefs. Nestor was a gentle ghost. Beneath the Surface was by far the most successful and most talked about exhibition that I have curated with undergraduates. Students in the class (judging by anonymous feedback) enjoyed the experience enormously, and students in the practicum in years since have wanted to hear more about this exhibition and often want to curate their own parafiction(s). As a class, creating a parafictional exhibition was remarkably successful - it was a catalyst for extraordinary research and information collection. The creation of the semi-fictional archive that underpinned the exhibition opened the door for an in-depth exploration of museum histories that repudiated any perceived neutrality of archives or museums. It was thus an immensely useful and generative teaching tool in terms of providing students with a critical lens through which to view conventional museum assumptions bound up in display, collection, and archiving, even as they drew attention to the pollution of local lakes.

As Le Couteur writes, (2015) referencing his own museal project - an homage to the lost collections of one John Affey, amateur explorer, ethnographer and whaler - 'Letting an object speak for itself is a standard conceptual metaphor in museum practice, and, like all standard conceptual metaphors, the more one examines it, the more contingent and bizarre it appears'. Objects cannot tell their own stories, and thus, as many museum theorists have pointed out, the authoritative voice of the curator speaks for (and often misinterprets) the object 
(Baxandall 1997; Le Couteur 2015: 40). Giving students the tools to understand how the voice of the curator is constructed was an epistemological encounter that became teleological only once the exhibition opened to the public. For students, Nestor and his quest for the Loch Ness monster 'represent[ed]... a quest for magic and wonder in a world many perceive as having lost its mystique' (Dendle (2006: 201). Perhaps for some people who viewed the exhibition, this was the case as well.

Received: 25 February, 2019 Finally accepted: 7 April, 2020

\section{Notes}

1 Keely McCavitt, 'The Man Behind the Archives', Beneath the Surface: The Archives of Arthur Nestor catalogue, 2014. http://archivesofnestor.weebly.com/catalogue.html. accessed 21 April 212020.

2 Many of the photos of Arthur Nestor used in the exhibition mimic existing photographs of Roy Mackal. There were many 'clues' in the exhibition like this, although as noted in the essay, we understood from the beginning that most people would not find or understand them all.

3 The students in this class were Victoria Delledonne, Claire Finlan, Ellen Groh, Tegan Avene Hadisi, Amy Harrington, Amelia Harris, Sohyun Kang, Sydney Kimber-Johnson, Keely McCavitt, Janeen Mills, Emily Peltier, Sam Roberts, Mackenzie Sinclair, Erik Skouris, Margaret Squires, and Jocelyn Tobin. The teaching assistant was Sophie Quick.

4 In 2012, the official name of the institution changed from University of Western Ontario to Western University, Canada, hence the discrepancy in the text.

5 Essential to the telling of Arthur Nestor's story in a compelling manner was the double creation of his office. In order to bring the audience into the story, we wanted to make sure that the recreation of Nestor's office in the gallery could be linked to an 'original'. In order to do this, we created an 'original' office in a room in the Visual Arts Building, took a photo of the 'original' office, which we placed in the exhibition with a replica of Nestor's office in three dimensions. Visitors to the exhibition could see a photo, ostensibly from the 1970s, of what they were looking at in front of them. Close observers would have noticed that both offices had the same plant - an impossibility given the forty years that had passed.

6 For more images, please visit the exhibition website at http://archivesofnestor.weebly. $\underline{\mathrm{com} /}$

7 Robin Cembalest, 'The Curator Vanishes: Period Room as Crime Scene', ARTnews, February 28 2013. https://www.artnews.com/art-news/news/mark-dion-curator-officein-minneapolis-2192l, accessed 9 September 2018.

8 The Curator's Office was part of the exhibition More/Real: Art in the Age of Truthiness, which would have influenced visitor expectations and alerted them to the fact that what they were seeing might not be 'true'.

9 Dieter Roelstraete, 'After the Historiographic Turn: Current Findings', e-flux (6) 2009. https://www.e-flux.com/journal/06/61402/after-the-historiographic-turn-current-findings/, accessed 9 September 2018.

10 See May Chew's (2015: 284) work on how Häussler's He Named Her Amber similarly works 'complicitously alongside ... longstanding colonial discourses'. 
11 Chanpreet Khurana, 'An Art Exhibition in Delhi Shows How Deception Can be Used as a Tool for Social Commentary', Scroll, 11 November 2018. https://scroll.in/magazine/900291/ an-art-exhibition-in-delhi-shows-how-deception-can-be-used-as-a-tool-for-socialcommentary, accessed 15 August 2019.

12 In my classes cabinets of curiosity are also used to introduce the relationship between the dark history of European colonization and the advent of museum collections.

13 This actually turned out not to be entirely the case as I did receive a confused email from a retired professor stating that he did not remember Arthur Nestor working in the Biology Department during the 1970s. I did not receive a reply to my explanation that Beneath the Surface was a speculative art work/exhibition.

14 Ulrich Magin claims that pre-1930s sightings were not common, and in fact there was no tradition of monster sightings in the Loch prior to the 1930s or even before the publication of Constance Whyte's popular book More Than a Legend, which claimed (incorrectly in Magin's opinion) a monster tradition.

15 Stephen Lyons, 'The Legend of Loch Ness' Nova, 12 January 1999. http://www.pbs.org/ wgbh/nova/ancient/legend-loch-ness.html, accessed 12 September 2018.

16 Ibid.

17 Bill Adams and Shane McCorristine, 'How the Search for Mythical Monsters Can Help Conservation in the Real World', Independent, 1 August 2017. https://www.independent. co.uk/environment/search-for-mythical-monsters-conservation-world-wildlife-fundbigfoot-loch-ness-a7868651.html, accessed 9 September 2018.

18 Jay Owens, 'The Age of Post-Authenticity and the Ironic Truths of Meme Culture', Medium, 11 April 2018. https://medium.com/s/story/post-authenticity-and-the-real-truths-of-memeculture-f98b24d645a0, accessed 12 September 2018.

\section{References}

Armstrong, E. (2013) 'On the Border of the Real', in Elizabeth Armstrong (ed) More/ Real: Art in the Age of Truthiness, 24-75, Munich, London, New York: Minneapolis Museum of Art and DelMonico Books.

Baxandall, M. (1997) 'Exhibiting Intention: Some Preconditions of the Visual Display of Culturally Purposeful Objects', in Ivan Karp and Steven D. Levine (eds) Exhibiting Cultures: The Poetics and Politics of Museum Display, 33-41, London and Washington: Smithsonian Institution Press.

Bondeson, J. (1999) The Feejee Mermaid and Other Essays in Natural and Unnatural History, Ithaca: Cornell University Press.

Chew, M. (2015) 'Archeological Detritus and the Bulging Archive: Staging He Named Her Amber at the Art Gallery of Ontario', in Thomas Allen and Jennifer Blair (eds) Material Cultures in Canada, 283-99, Waterloo: Wilfrid Laurier Press.

Dendle, P. (2006) 'Cryptozoology in the Medieval and Modern Worlds', Folklore, 117 (2) 190-206.

Foster, H. (2017) Bad New Days: Art, Criticism, Emergency, London: Verso. 
Hurn, S. (2017) 'Introduction', in Samantha Hurn (ed) Anthropology and Cryptozoology: Exploring Encounters with Mysterious Creatures, 1-11, London and New York: Routledge.

Lambert-Beatty, C. (2009) 'Make Believe: Parafiction and Plausibility', October, (129) 5184.

(2012) More Real? Art in the Age of Truthiness, New York: Prestel.

Laurent, B. (2017) 'Monster of Missing Link? The Mermaid and the Victorian Imagination', Cahiers victoriens et édouardiens, (85) 1-17.

Lawton, J. (1996) 'Nessiteras Rhombopteryx', Oikos, 77 (3) 378-80.

Le Couteur, P. (2015) 'Fictive Museums and the Poetics of Mislabeling', Performance Research, 20 (1) 36-47.

Lehn, W.H. (1979) 'Atmospheric Refraction and Lake Monsters' Science, 205 (4402) 183-5.

Mackal, R. (1976) Monsters of Loch Ness, Athens OH: Swallow Press.

MacKay, G. (2009) 'Brilliant Disguise', Canadian Art, 26 (4) 82-7.

McLeod, E. (2013) 'By a Wing and a Tale: Authenticating the Archive in Mohamad-Said Baalbaki's "Al Buraq I The Prophet's Human-Headed Mount"', RACAR: revue d'art canadienne/Canadian Art Review, 38 (1) 97-105.

Magin, U. (2016) 'Necessary Monsters: Claimed "Crypto-Creatures” Regarded as Genii Locii', Time and Mind, 9 (3) 211-21.

Pandora, K. (2017) 'The Permissive Precincts of Barnum's and Goodrich's Museums of Miscellaneity: Lessons in Knowing Nature for New Learners', in Carin Berkowitz and Bernard Lightman (eds) Science Museums in Transition: Cultures of Display in Nineteenth-Century Britain and America, ebook, 36-64, Pittsburgh: University of Pittsburgh Press.

Polliquin, R. (2012) The Breathless Zoo: Taxidermy and the Cultures of Longing, Pennsylvania: Penn State University Press.

Reiss, B. (2010) The Showman and the Slave, Cambridge: Harvard University Press.

Schneider, W. and Wallis, P. (1973) 'An Alternate Method of Calculating the Population Density of Monsters in Loch Ness', Liminology and Oceanography, 18 (2) 343.

Scott, P. and Rines, R. (1975) 'Naming the Loch Ness Monster' Nature, (258) 466-8.

Simpson, G. (1984) 'Mammals and Cryptozoology', Proceedings of the American Philosophical Society, 128 (1) 1.

Zarzynski, J. (1984) Champ: Beyond the Legend, New York: MZ Information. 


\begin{abstract}
Author:
Kirsty Robertson

Kirsty Robertson is Associate Professor of Contemporary Art and Director of Museum and Curatorial Studies at Western University, Canada (London, Ontario). Her pedagogy involves curating speculative and experimental exhibitions with students. In her academic work, Robertson has published widely on activism, visual culture, and museums. Her book, Tear Gas Epiphanies: Protest, Culture, Museums was published by McGill-Queen's University Press in May, 2019. Her work on museums has expanded into a new project focused on small and micro- collections that repurpose traditional museum formats for critical and politically radical projects. In addition, Robertson is a founding member of the Synthetic Collective, a group of artists, scientists, and cultural researchers working on plastics pollution in the Great Lakes Region and co-lead on A Museum for Future Fossils, an ongoing project focused on responding curatorially to ecological crisis.
\end{abstract}

For further information, please see www.kirstymairirobertson.com.

Email: Kirsty.robertson@uwo.ca

Phone: (011) 519-661-2111 x 83440

Kirsty Robertson

Department of Visual Arts

Western University, Canada

London, Ontario,

Canada

N6A 3K7 